\title{
Gender-specific usage of intramyocellular lipids and glycogen during exercise
}

Citation for published version (APA):

Zehnder, M. G., Ith, M., Kreis, R., Saris, W. H. M., Boutellier, U., \& Boesch, C. (2005). Gender-specific usage of intramyocellular lipids and glycogen during exercise. Medicine and Science in Sports and Exercise, 37(9), 1517-1524. https://doi.org/10.1249/01.mss.0000177478.14500.7c

Document status and date:

Published: 01/01/2005

DOI:

10.1249/01.mss.0000177478.14500.7c

Document Version:

Publisher's PDF, also known as Version of record

\section{Please check the document version of this publication:}

- A submitted manuscript is the version of the article upon submission and before peer-review. There can be important differences between the submitted version and the official published version of record.

People interested in the research are advised to contact the author for the final version of the publication, or visit the DOI to the publisher's website.

- The final author version and the galley proof are versions of the publication after peer review.

- The final published version features the final layout of the paper including the volume, issue and page numbers.

Link to publication

\footnotetext{
General rights rights.

- You may freely distribute the URL identifying the publication in the public portal. please follow below link for the End User Agreement:

www.umlib.nl/taverne-license

Take down policy

If you believe that this document breaches copyright please contact us at:

repository@maastrichtuniversity.nl

providing details and we will investigate your claim.
}

Copyright and moral rights for the publications made accessible in the public portal are retained by the authors and/or other copyright owners and it is a condition of accessing publications that users recognise and abide by the legal requirements associated with these

- Users may download and print one copy of any publication from the public portal for the purpose of private study or research.

- You may not further distribute the material or use it for any profit-making activity or commercial gain

If the publication is distributed under the terms of Article $25 \mathrm{fa}$ of the Dutch Copyright Act, indicated by the "Taverne" license above, 


\title{
Gender-Specific Usage of Intramyocellular Lipids and Glycogen during Exercise
}

\author{
MONICA ZEHNDER ${ }^{1,2,3}$, MICHAEL ITH ${ }^{2}$, ROLAND KREIS ${ }^{2}$, WIM SARIS $^{3}$, URS BOUTELLIER ${ }^{1}$, and \\ CHRIS BOESCH ${ }^{2}$ \\ ${ }^{I}$ Exercise Physiology, Institute for Human Movement Sciences, Swiss Federal Institute of Technology Zurich and Institute \\ of Physiology, University of Zurich, Zurich, SWITZERLAND; ${ }^{2}$ Department of Clinical Research, MR Spectroscopy and \\ Methodology, University of Bern, Bern, SWITZERLAND; and ${ }^{3}$ Nutrition and Toxicology Research Institute Maastricht, \\ Department of Human Biology, Maastricht University, THE NETHERLANDS
}

\begin{abstract}
ZEHNDER, M, M. ITH, R. KREIS, W. SARIS, U. BOUTELLIER, and C. BOESCH. Gender-Specific Usage of Intramyocellular Lipids and Glycogen during Exercise. Med. Sci. Sports Exerc., Vol. 37, No. 9, pp. 1517-1524, 2005. Purpose: Gender-specific differences in substrate utilization during exercise have been reported, typically such that women rely more on fat than men. This study investigated whether gender differences exist in the utilization of intramyocellular lipids (IMCL) and glycogen Methods: IMCL and glycogen, as well as total fat and carbohydrate (CHO) oxidation were measured in nine males and nine females before, during, and after an endurance exercise. The trained subjects exercised on a bicycle ergometer at 50\% maximal workload for $3 \mathrm{~h}$. IMCL and glycogen were determined in the thigh by magnetic resonance spectroscopy. Oxygen uptake $\left(\mathrm{V}_{2}\right)$ and carbon dioxide production were determined by open circuit spirometry to calculate total fat and $\mathrm{CHO}$ oxidation. Relative power output, percent of maximum heart rate, $\% \mathrm{VJO}_{2 \text { peak }}$, and respiratory exchange ratio were the same Results: Average fat oxidation was the same, whereas CHO oxidation was significantly higher in males compared with females. The relative contribution of these fuels to total energy used were similar in males and females. Males and females depleted IMCL and glycogen significantly $(P<0.001)$ during the 3-h exercise. IMCL levels at rest $(P<0.05)$ and its depletion during exercise $(P<0.001)$ were significantly higher in males compared with females, whereas glycogen was stored and used in the same range by both genders Conclusion: During this 3-h exercise, energy supplies from fat and $\mathrm{CHO}$ were similar in both genders, and males as well as females reduced their IMCL stores significantly. The larger contribution of IMCL during exercise in males compared with females could either be a result of gender-specific substrate selection, or different long-term training habit. Key Words: ${ }^{1} \mathrm{H}$ - AND ${ }^{13} \mathrm{C}$ - MAGNETIC RESONANCE SPECTROSCOPY, FAT AND CARBOHYDRATE METABOLISM, ENDURANCE EXERCISE AND TRAINING
\end{abstract}

$\mathrm{T}$ The main fuels oxidized by the muscle for energy production during exercise are fat and carbohydrates (CHO). $\mathrm{CHO}$ is available within the muscle fiber (glycogen) and from blood glucose (breakdown of liver glycogen). Fat is available from lipid droplets within the muscle fiber (intramyocellular lipids, IMCL) as well as from plasma free fatty acids (FFA) from lipolysis. The relative contribution of these substrates to energy expenditure depends on the exercise intensity and duration, diet, and training status of the subject. It has also been suggested that substrate use and the relative contribution of substrates are gender dependent. Although several studies have shown no gender differences in substrate utilization $(24,26)$, the majority of studies (e.g., $(6,8,13))$ have reported that women rely more on fat oxidation during prolonged exercise than men. Furthermore, men have been shown to acquire a

\footnotetext{
Address for correspondence: Chris Boesch, MD, PhD, MR-Center 1 University and Inselspital CH-3010 Bern, Switzerland; E-mail: chris.boesch@insel.ch.

Submitted for publication December 2004.

Accepted for publication April 2005.
}

0195-9131/05/3709-1517/0

MEDICINE \& SCIENCE IN SPORTS \& EXERCISE ${ }_{\circledast}$

Copyright (C) 2005 by the American College of Sports Medicine

DOI: $10.1249 / 01 . m s s .0000177478 .14500 .7 \mathrm{c}$ greater proportion of their energy from muscle glycogen oxidation than women $(6,26)$.

Recent studies accumulate evidence that IMCL are an important energy source during exercise $(16,25,32,33)$, although this has not been shown in all studies $(11,17)$. It is still controversial and a matter of debate how the utilization of IMCL is regulated, and how much IMCL contribute to the total fat oxidation and total energy consumption during endurance exercise $(4,25)$. It is also not clear whether gender differences exist in the contribution of IMCL to energy needs and in the storage of IMCL, and whether full IMCL stores influence glycogen utilization during exercise. There are only two more studies, in which males and females were investigated in terms of IMCL metabolism at the same time. One study found decreased IMCL levels in females after exercise, whereas in males IMCL levels were unaffected by exercise (30). The other study measured no difference in IMCL reduction between males and females (36). With regard to the storage of IMCL, Thamer et al. (31) observed significantly higher IMCL in soleus muscle in males compared with females, and slightly but not significantly higher IMCL in tibialis muscle in female than in male subjects.

These controversial results may be partly due to the methodology used (34). Muscle biopsies and, on the other hand, indirect stable isotopic tracer methods (25) have been used for many years. It has been shown that IMCL concen- 
trations measured in repeated biopsy samples are variable, with a CV of 20-26\% (35). Morphometrical analysis, on the other hand, is observer dependent (14). Assumptions that have to be made for the application of stable isotopes (25) do not always hold true because (a) the contribution from circulating plasma triglycerides is neglected, and (b) a potential contribution from local extramyocellular lipids (EMCL) would lead to an overestimation of the IMCL oxidation. On the other hand, an advantage of stable isotope tracer methods is that the rate of utilization is assessed directly during the activity, and is not dependent on calculating differences between pre- and postexercise measurements.

Localized ${ }^{1} \mathrm{H}$-magnetic resonance spectroscopy can be used to measure IMCL concentrations noninvasively $(4,27)$. Based on the observation that two methylene resonances from different fat compartments can be distinguished in skeletal muscle (27), the signals from IMCL (lipid droplets within a muscle cell) and EMCL (fat layers outside the muscle cell) have been characterized (4). In contrast to indirect methods, ${ }^{1} \mathrm{H}-\mathrm{MRS}$ of muscle tissue yields a resonance signal that is directly proportional to the concentration of IMCL, thus allowing a determination of absolute IMCL concentrations (3). Repeated ${ }^{1} \mathrm{H}$-MRS measurements allow for a follow up of depletion and replenishment of a major intramuscular component. Because repeated MR spectra can be obtained from exactly the same location in a muscle, this method is less susceptible to regional variations of IMCL $(4,14,15)$ than repeated biopsies. In addition, the simultaneous combination of ${ }^{1} \mathrm{H}$ - and ${ }^{13} \mathrm{C}$-MRS allows determining muscle energy stores before and after endurance exercise in the same examination.

The aims of this study were to investigate 1) whether it is possible with an adequate/appropriate endurance exercise protocol to reduce IMCL and glycogen to a significant degree in the $m$. vastus intermedius in both males and females, and 2) whether there is a gender difference in the utilization of IMCL and glycogen during exercise at the same relative intensity in a group of trained males and females.

\section{METHODS}

Subjects. Nine male and nine female cyclists or triathletes participated in the study. All were well trained, involved in endurance exercise training programs for at least three times a week ( $\geq 2 \mathrm{~h}$ per training session), and with a training history of at least $3 \mathrm{yr}$. The recruited females were all eumenorrheic and the 3-h exercise was performed during the follicular phase between the third and eighth day. The mean \pm SD age and weight for males versus females were $34 \pm 4$ versus $30 \pm 4 \mathrm{yr}$ and $73.9 \pm 8.4$ versus $58.9 \pm 5.6$ $\mathrm{kg}$. There was no difference in the percentage of measured body fat between genders (males: $9.2 \pm 5.5 \%$; females: 8.8 $\pm 3.1 \%$ ). All subjects signed an informed consent form, including nutritional and activity guidelines, before admission into the study. The institutional ethics committee approved the experimental protocol.
TABLE 1. Daily average intake of macronutrients and energy by male and female subjects during the $2 \mathrm{~d}$ before exercise.

\begin{tabular}{lccc}
\hline & & Males & Females \\
\hline CHO & $(\%$ energy $)$ & $48 \pm 9$ & $55 \pm 9$ \\
Fat & & $41 \pm 8$ & $35 \pm 8$ \\
Protein & & $14 \pm 3$ & $13 \pm 2$ \\
\hline & & $529 \pm 129^{*}$ & $500 \pm 112$ \\
CHO & $(\mathrm{g})$ & $215 \pm 100^{* *}$ & $112 \pm 21$ \\
Fat & & $157 \pm 53^{* *}$ & $93 \pm 22$ \\
Protein & & & \\
\hline & & $19,772 \pm 5757^{* *}$ & $12,672 \pm 1961$ \\
Energy & $(\mathrm{kJ})$ & $8.0 \pm 2.5$ & $7.6 \pm 2.3$ \\
\hline & & $3.3 \pm 1.8$ & $2.1 \pm 0.4$ \\
OCHO & $\left(\mathrm{g} \cdot \mathrm{kg}^{-1}\right.$ lean bw) & $2.4 \pm 0.9$ & $1.8 \pm 0.4$ \\
Fat & & $301 \pm 112$ & $238 \pm 44$ \\
Protein & &
\end{tabular}

Values are means $\pm \mathrm{SD} ; N=9$ for each gender.

${ }^{\star *} P<0.01$; ${ }^{\star} P<0.05$ significantly different from female.

Preliminary testing. To evaluate training status and maximal workload, the subjects performed a maximal workload $\left(\mathrm{W}_{\max }\right)$ test on a cycle ergometer (Ergometrics $800 \mathrm{~S}$, Ergoline, Bitz, Germany) at least 1 wk before the experiment. The test took place after an overnight fast that followed a day without exercise and with consumption of carbohydrate-rich meals. Male subjects started exercising at a work rate of $100 \mathrm{~W}$ for $2 \mathrm{~min}$; females at a work rate of $60 \mathrm{~W}$ for $2 \mathrm{~min}$. Resistance was increased for males in $30-\mathrm{W}$ steps, for females in $20-\mathrm{W}$ steps every 2 min until exhaustion. Throughout the whole test, the pedal rate had to been kept above $80 \mathrm{rpm}$. Oxygen uptake $\left(\dot{\mathrm{VO}}_{2}\right)$, carbon dioxide production $\left(\dot{\mathrm{VCO}}_{2}\right)$, and heart rate were continuously monitored. $\dot{\mathrm{VO}}_{2}$ and $\dot{\mathrm{VCO}}_{2}$ were determined by an open-circuit system (Oxycon $\beta$, Jäger, Höchberg, Germany), and cardiac frequency was measured by a heart rate monitor (Vantage NV, Polar Electro, Kempele, Finland). The highest intensity maintained by the subjects for at least 1 min by a pedal rate above 80 rpm defined the subjects' voluntary $\mathrm{W}_{\text {max }}$ and was scored as $100 \% . \dot{\mathrm{VO}_{2 p e a k}}$ was defined as the highest value reached in a 30 -s period.

Diet monitoring. Because IMCL concentrations can be influenced by diet (8), short-term nutritional intake was standardized and monitored. During the $2 \mathrm{~d}$ before the trials, diet was controlled and volunteers received a nutrition protocol for each meal (breakfast, lunch, dinner, and snacks) and were instructed to choose from a selection of food and beverages. Detailed food exchange lists with serving sizes (e.g., dried fruits, gingerbread, rice pudding, pasta, rice, soft drinks, dairy products, beef, tuna, tofu) were used for nutrient recommendations. Any change of the diet recommendation had to be documented by the volunteers. The day before the test, an additional amount of at least $0.75 \mathrm{~g}$ fat $\cdot \mathrm{kg}^{-1}$ body weight (bw) was provided by 3-4 fat-rich snacks to replenish IMCL stores. Subjects were also asked to renounce caffeine-containing beverages $24 \mathrm{~h}$ before exercise. The food records (Table 1) for carbohydrate, fat, and protein contents as well as for the total amount of energy were analyzed by a computer-based nutrient analysis program (EBIS 2.0; E+D Partner, Stuttgart, Germany). 
Experimental protocol. For the exercise endurance test, subjects reported after a day without any exercise and an overnight fast to the MR-Center of the Inselspital in Bern (Switzerland) at 7:00 a.m. and were positioned in the magnet for the magnetic resonance measurements. The preexercise measurements of IMCL and glycogen were obtained between 7:30 a.m. and 9:00 a.m. The exercise on a bicycle ergometer started at 9:15 a.m. and continued for $3 \mathrm{~h}$ with constant revolutions $(70-75 \mathrm{rpm})$ at an intensity of $50 \%$ $\mathrm{W}_{\max }$, corresponding to $60-65 \% \mathrm{~V}_{2} \mathrm{O}_{2 \text { peak }}$. This exercise intensity was chosen because it is expected to optimize fat oxidation (1). The number of revolutions per minute were carefully supervised because higher frequencies seem to prefer the activation of type II muscle fibers (20), which, in turn, contain less IMCL than type I fibers (15). During the endurance test, heart rate was recorded continuously (Polar Electro, Kempele, Finland). To determine total fat and $\mathrm{CHO}$ oxidation by indirect calorimetry, subjects were connected by a face mask with a gas analyzer for $\dot{\mathrm{VO}}_{2}, \dot{\mathrm{V}}_{2}$, and volume (Oxycon $\beta$, Jäger, Höchberg, Germany). After calibration of the gas analyzers before each experiment, expired gases were measured intermittently (every $18 \mathrm{~min}$ for at least $6 \mathrm{~min}$ ) for $\mathrm{O}_{2}$ (paramagnetic) and $\mathrm{CO}_{2}$ (infrared). During cycling, the subjects were allowed to drink water $\mathrm{ad}$ libitum. Immediately after exercise, subjects were repositioned in the magnet and the same MR measurements that had been taken before the 3-h cycling test were repeated.

Magnetic resonance (MR). Muscle glycogen and IMCL stores in the $m$. quadriceps femoris of the right leg were measured sequentially within the same session. An entire session consisted of image acquisition, ${ }^{13} \mathrm{C}$ - and ${ }^{1} \mathrm{H}$ MRS and lasted about 90 min. MR imaging and spectroscopy examinations were done on a clinical 1.5-T MR system (SIGNA, General Electric, Milwaukee WI), using a flexible, ${ }^{13} \mathrm{C} /{ }^{1} \mathrm{H}$ dual tuned surface coil (Medical Advance, Milwaukee, WI) placed over the m. quadriceps femoris. A cast fixed the right leg such that the shape of the thigh muscles was the same before and after exercise and that the coil could be placed identically. Careful and reproducible placement of the ${ }^{1} \mathrm{H}$-MRS voxel, that is, a sensitive volume where the IMCL signal is coming from, is crucial. Following localizer series (gradient echo, $30^{\circ}$ flip angle, repetition time (TR) of $100 \mathrm{~ms}$, echo time (TE) of $6.8 \mathrm{~ms})$, a volume $(11 \times 12 \times$ $18 \mathrm{~mm}^{3}$ ) without any sign of fatty infiltration was defined (Fig. 1). The voxel was positioned in the $m$. vastus intermedius close to the femoral bone because the fixation of the muscle by the bone helps to achieve a better agreement in repositioning the voxel. Measuring IMCL by ${ }^{1} \mathrm{H}-\mathrm{MRS}, m$. vastus intermedius shows a higher reproducibility, less contamination of subcutaneous EMCL, and therefore a better separation of IMCL and EMCL compared with $m$. vastus lateralis (3) In addition, we found in a recent study that m.vastus intermedius is representative for IMCL utilization of the other vastus muscles during this kind of exercise (37).

${ }^{1} \mathrm{H}-\mathrm{MR}$ spectra were recorded by an optimized PRESS sequence with a TE of $20 \mathrm{~ms}$, a TR of $3000 \mathrm{~ms}, 128$ acquisitions, and 16 phase rotation steps. Fitting of IMCL and EMCL in water suppressed spectra by four Voigt lines

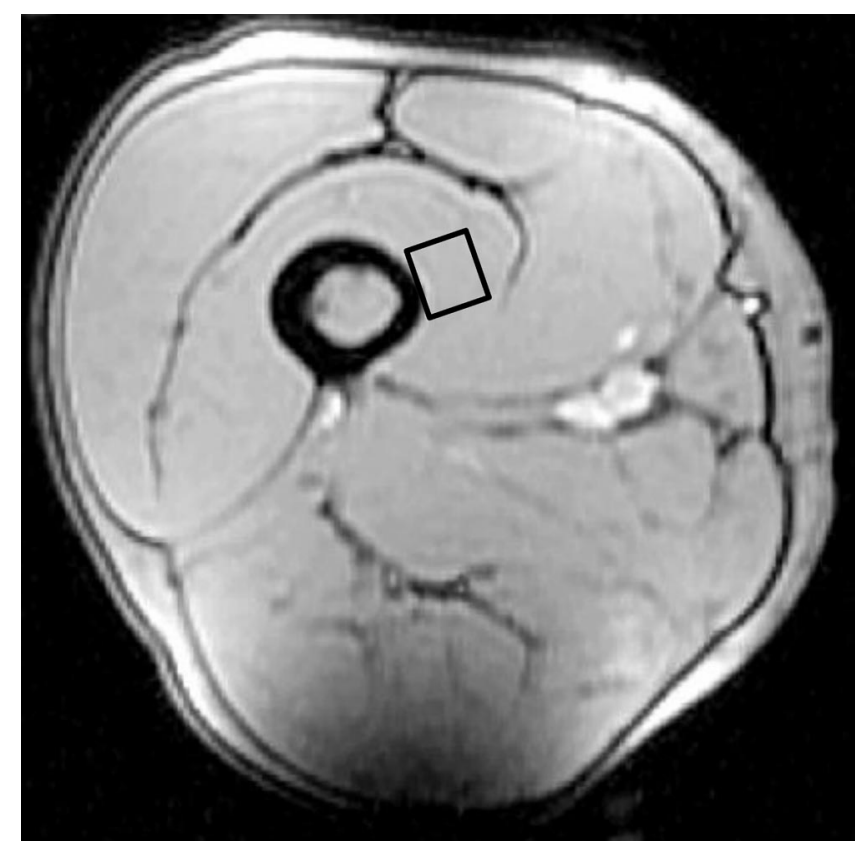

FIGURE 1-Transversal MR image of a thigh with voxel placed in $\boldsymbol{m}$. vastus intermedius. The voxel positioning avoids any sign of adipose tissue (extramyocellular lipids) in fasciae or subcutaneous fat.

each $(3,4)$ was followed by absolute quantification of IMCL (mmol. $\mathrm{kg}^{-1}$ w.w.), based on the signal of water in a TE series of free induction decays obtained without water suppression (3). Figure 2 shows representative spectra of one volunteer before and after the exercise, including the difference spectrum that shows almost exclusively the IMCL resonances that are used to quantify this metabolite.

Glycogen was measured by ${ }^{13} \mathrm{C}$-MRS using a pulse-andacquire sequence $(\mathrm{TR}=301 \mathrm{~ms}$, adiabatic pulse). A partially home built second channel was used for ${ }^{1} \mathrm{H}$-decoupling during ${ }^{13} \mathrm{C}$-spectroscopy and for nuclear Overhauser

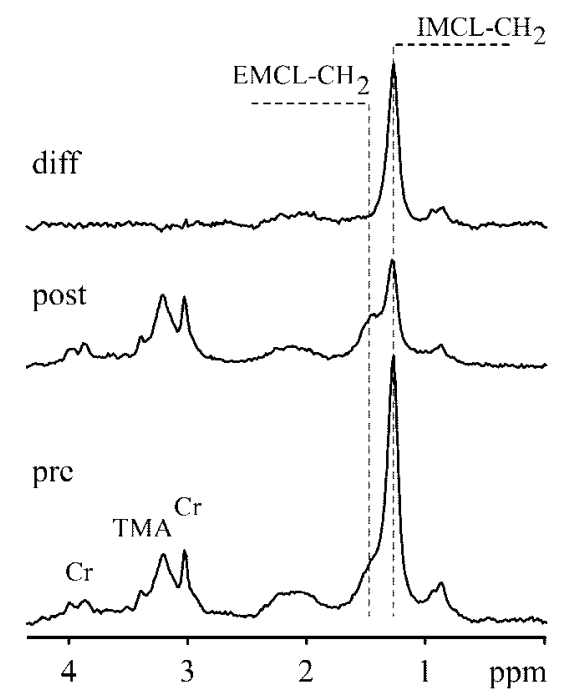

FIGURE 2- ${ }^{1}$ H-MR spectra before (lower trace) and after 3-h exercise (middle trace) of a male subject. The difference spectrum between preand postexercise (top trace) shows the resonance lines of intramyocellular lipids (IMCL). The peak of IMCL-methylene groups (IMCLCH2) is used for the determination of IMCL concentrations. EMCL, extramyocellular lipids. 
enhancement. For each session 6000 averaged acquisitions added up to the measured ${ }^{13} \mathrm{C}$-spectrum. While the center of the ${ }^{13} \mathrm{C}$-coil was placed above the $m$. rectus femoris, the glycogen signal originated from all muscles of the quadriceps femoris due to the large dimensions of the coil $(11 \times$ $11 \mathrm{~cm}^{2}$ ). The resulting difference between the sensitive volumes for glycogen and IMCL should not influence the findings of this study, because we could show in another MR study that (a) the IMCL depletion was comparable among all vastus muscles, and (b) m.vastus intermedius had an absolute amount of IMCL that was quite representative for all vastus muscles (37). The glycogen signal was calibrated by the signal area of creatine in the ${ }^{13} \mathrm{C}$-spectrum because the concentration of creatine is expected to be gender independent. This assumption has been validated by the ${ }^{1} \mathrm{H}-\mathrm{MR}$ signal of creatine in this study.

Borg scale. During the 3-h exercise, each subject rated his or her perceived exertion according to the Borg scale (5). After the standardized question of "how do you score the exertion?" the subject read from a visible scale a number between 6 (very, very light) and 20 (very, very hard). The recording was performed always by the same investigator.

Determination of body fat-free mass, total fat and $\mathrm{CHO}$ oxidation, and total energy used. Skinfold was measured with a caliper (GPM Siber Hegner, Zurich, Switzerland) at 10 different locations of the body (cheek below temple, throat, chest, midaxillary, suprailiac, abdomen, triceps, subscapular, calf, and thigh above patella) before each 3-h exercise. One investigator (M.Z.) carried out all the individual measurements. The average of three determinations of each measuring site was taken as a valid result for the calculation of the fat-free mass following a formula given by Sinning et al. (28).

Whole-body fat and $\mathrm{CHO}$ oxidation rates were estimated from expired $\dot{\mathrm{V}}_{2}$ and $\dot{\mathrm{V}} \mathrm{CO}_{2}$, assuming the nonprotein respiratory quotient (21).

Fat oxidation $\left(\mathrm{g} \cdot \mathrm{min}^{-1}\right)=\left(1.695 \cdot \dot{\mathrm{V}} \mathrm{O}_{2} \mathrm{~mL} \cdot \mathrm{min}^{-1}\right.$

$$
\left.-1.701 \cdot \dot{\mathrm{V} C O} \mathrm{~mL}_{2} \cdot \mathrm{min}^{-1}\right) / 1000
$$

CHO oxidation $\left(\mathrm{g} \cdot \mathrm{min}^{-1}\right)=\left(4.585 \cdot \dot{\mathrm{V} C O} \mathrm{~mL}_{2} \cdot \mathrm{min}^{-1}\right.$

$$
\left.-3.226 \cdot \dot{\mathrm{V}} \mathrm{O}_{2} \mathrm{~mL} \cdot \mathrm{min}^{-1}\right) / 1000
$$

Total energy was calculated by adding total energy expenditure from fat and $\mathrm{CHO}$ oxidations.

The contribution of IMCL and muscle glycogen to the total energy expenditure during exercise was estimated on the assumption of $10 \mathrm{~kg}$ of active muscle mass for males and $8.8 \mathrm{~kg}$ for females (estimated from the MR localizer images).

Blood analysis. Lactate and glucose were determined in capillary blood from the earlobe at rest and then every 30 min until the end of exercise.

Statistical analysis. Differences within each group were tested by two-way analysis of variance (MANOVA) for repeated measures, followed by Bonferroni adjustment for multiple comparisons (SPSS 11.0). Differences between females and males were analyzed by a two-sided unpaired $t$-test. Linear regression analysis was performed with standard procedures, using Excel XP (Microsoft). Statistical significance was set at $P<0.05$.

\section{RESULTS}

Preliminary testing. The maximum power $\mathrm{W}_{\max }$ that has been produced by at least 1 min was significantly $(P<$ $0.001)$ higher in males $(368 \pm 22 \mathrm{~W})$ than in females $(240$ $\pm 20 \mathrm{~W}$ ). Maximal oxygen uptake $\dot{\mathrm{VO}}_{2 \text { peak }}$ was also significantly $(P<0.01)$ higher in males $(4363 \pm 488$ $\mathrm{mL} \cdot \mathrm{min}^{-1}=65 \pm 7 \mathrm{~mL} \cdot \mathrm{min}^{-1} \cdot \mathrm{kg}^{-1}$ lean bw) than in females $\left(2853 \pm 325 \mathrm{~mL} \cdot \mathrm{min}^{-1}=53 \pm 4 \mathrm{~mL} \cdot \mathrm{min}^{-1} \cdot \mathrm{kg}^{-1}\right.$ lean bw). Relative parameters, however, did not differ between genders, such as $\dot{\mathrm{VO}}_{\text {2peak }}$ standardized by $\mathrm{W}_{\text {max }}$ (males, $11.9 \pm 1.1 \mathrm{~mL} \dot{\mathrm{VO}}{ }_{2} \cdot \mathrm{min}^{-1} \cdot \mathrm{W}^{-1}$; females, $11.9 \pm$ $0.7 \mathrm{~mL} \mathrm{VO}_{2} \cdot \mathrm{min}^{-1} \cdot \mathrm{W}^{-1}$ ), and also maximal heart rate per minute (males, $182 \pm 11$ beats. $\mathrm{min}^{-1}$; females, $183 \pm 10$ beats. $\left.\min ^{-1}\right)$.

Diet analyses. Table 1 shows that there was no difference between genders in the average intake per lean bw of CHO, fat, protein $\left(\mathrm{g} \cdot \mathrm{d}^{-1} \cdot \mathrm{kg}^{-1}\right.$ lean bw), and energy $\left(\mathrm{kJ} \cdot \mathrm{kg}^{-1}\right.$ lean bw) before the trial. In relation to the total energy uptake, the percentage intake of fat, $\mathrm{CHO}$, and protein was also not significantly different between genders.

Experimental protocol. As the absolute power output $\mathrm{W}_{\max }$ on the bicycle ergometer showed a significant differ-

\begin{tabular}{|c|c|c|c|c|c|}
\hline Males $(N=9)$ & 1 Hour & 2 Hour & 3 Hour & $\begin{array}{l}P \text { Between } \\
\text { Hours }\end{array}$ & Average \\
\hline $\begin{array}{l}\% \dot{\mathrm{VO}_{2 \text { peak }}} \\
\% \text { max heart rate }(N=8) \\
\text { RER } \\
\text { Energy used per watt }\left(\mathrm{kJ} \cdot \mathrm{W}^{-1}\right) \\
\text { Energy \% from fat }\end{array}$ & $\begin{aligned} 61 & \pm 7 \\
68 & \pm 7^{\star} \\
0.90 & \pm 0.04 \\
19.3 & \pm 1.4 \\
28 & \pm 12\end{aligned}$ & $\begin{aligned} 61 & \pm 8 \\
72 & \pm 8 \\
0.88 & \pm 0.03 \\
18.7 & \pm 1.6 \\
36 & \pm 11\end{aligned}$ & $\begin{aligned} 63 & \pm 8 \\
76 & \pm 8 \\
0.85 & \pm 0.02 \\
19.1 & \pm 1.6 \\
46 & \pm 6\end{aligned}$ & $\begin{array}{r}0.002 \\
<0.001 \\
<0.001 \\
0.060 \\
<0.001\end{array}$ & $\begin{aligned} 62 & \pm 7 \\
72 & \pm 8 \\
0.88 & \pm 0.03 \\
19.0 & \pm 1.5 \\
37 & \pm 9\end{aligned}$ \\
\hline Females $(N=9)$ & 1 Hour & 2 Hour & 3 Hour & $\begin{array}{c}P \text { Between } \\
\text { Hours }\end{array}$ & Average \\
\hline
\end{tabular}

TABLE 2. Comparison of measured parameters in males and females during the 3-h exercise.

Values are means $\pm \mathrm{SD}$.

${ }^{*} P<0.05$ significant differences between males and females, $P$ values indicate significance of differences between the single hours. 

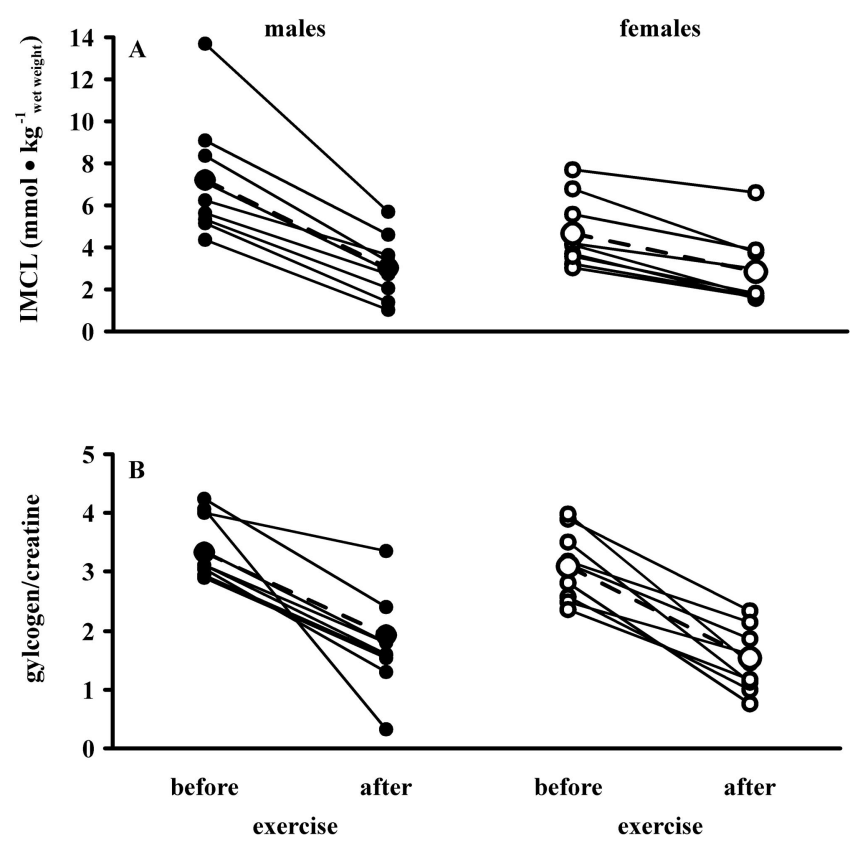

FIGURE 3-IMCL (A) and glycogen (B) levels of nine males and nine females before and after a 3 -h exercise. The group averages are shown in dotted lines.

ence between males and females, the workload of $50 \%$ $\mathrm{W}_{\max }$ during the endurance exercise, corresponding to 184 $\pm 11 \mathrm{~W}$ for males and $120 \pm 10 \mathrm{~W}$ for females, respectively, was also different $(P<0.001)$. In contrast, the percentage rate of the maximal heart rate, of $\dot{\mathrm{V}}_{2 \text { peak }}$, as well as the RER, was the same in males and females (Table 2 ). The RER changed significantly only within the group over time. Both genders scored the perceived exertion during exercise similarly, which was between 12 (fairly light) and 14 (somewhat hard). Average oxygen uptake per workload (males, $14.54 \pm 1.19 \mathrm{~mL} \mathrm{O} \mathrm{min}^{-1} \cdot \mathrm{W}^{-1}$; females, $15.36 \pm 0.08 \mathrm{~mL} \mathrm{O} \min ^{-1} \cdot \mathrm{W}^{-1}$ ) was the same in both genders.

Magnetic resonance. Figures $3 \mathrm{~A}$ and $\mathrm{B}$ show IMCL and glycogen values before and after exercise. There was a higher IMCL concentration in males compared with females before exercise $(P=0.04)$, and indistinguishable values after exercise. The reduction of IMCL during the 3-h trial was highly significant in both males and females $(P<$ 0.001 ), but was larger in males compared with females in absolute units (males, $4.2 \pm 1.6 \mathrm{mmol} \cdot \mathrm{kg}^{-1}$ w.w.; females, $1.8 \pm 0.6 \mathrm{mmol} \cdot \mathrm{kg}^{-1}$ w.w., $\left.P<0.001\right)$ as well as in relative terms (males, $59 \pm 11 \%$; females, $42 \pm 14 \%, P=0.01$ ). Figure 4 shows a strong correlation between resting IMCL concentration before exercise and the reduction of IMCL during the 3-h trial for the pooled data of both genders.

Glycogen concentrations before and after exercise in males and females showed no difference between gender in the displayed concentrations (Fig. 3B) or in the depletion (males, $1.68 \pm 0.85 \mathrm{U}$, corresponding to $49 \pm 20 \%$; females, $1.62 \pm 0.58 \mathrm{U}$, corresponding to $52 \pm 15 \%$ ).

Glycogen utilization during the 3-h exercise was $334 \mathrm{kcal}$ for males and $264 \mathrm{kcal}$ for females, respectively, corresponding to 13 and $16 \%$ of total energy used (no significant

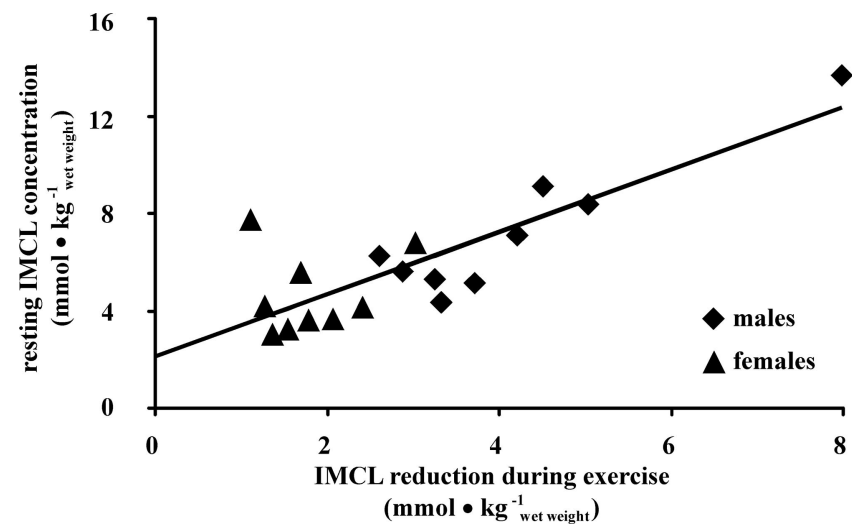

FIGURE 4-Correlation of IMCL concentrations before exercise and the reduction during exercise for nine males and nine females combined. The regression line is described by $y=2.11+1.28 x, P<0.001$, $\mathbf{r}=\mathbf{0 . 8 3}$.

difference). The depletion of IMCL during the 3-h exercise was $329 \mathrm{kcal}$ for males and $117 \mathrm{kcal}$ for females, corresponding to 13 and $6.6 \%$ of total energy $(P<0.01)$.

In males and females, there was no correlation between the total fat oxidation and the IMCL concentration at rest (males: $\mathrm{r}=0.08, P=0.82$; females: $\mathrm{r}=0.05, P=0.89$ ) or the IMCL depletion (males: $\mathrm{r}=0.01, P=0.97$; females: $\mathrm{r}=0.33, P=0.38$ ). The same applies to $\mathrm{CHO}$ oxidation and glycogen concentration at rest (males: $\mathrm{r}=0.21, P=$ 0.59; females: $\mathrm{r}=0.04, P=0.92$ ) and to $\mathrm{CHO}$ oxidation and glycogen depletion (males: $\mathrm{r}=0.12, P=0.76$; females: $\mathrm{r}=0.32, P=0.40)$. There was no correlation between $\dot{\mathrm{V}} \mathrm{O}_{2 \text { peak }}$ and resting IMCL in males $(\mathrm{r}=0.04, P=0.91)$, yet a trend could be identified in females $(\mathrm{r}=0.52, P=$ $0.15)$.

Fat oxidation and $\mathrm{CHO}$ oxidation. Figure 5 shows the fat and $\mathrm{CHO}$ oxidation rates $\left(\mathrm{mg} \cdot \mathrm{kg}^{-1}\right.$ lean bw. $\left.\mathrm{min}^{-1}\right)$ during the single hour, and the average over the 3-h exercise for males and females. Average total fat oxidation $\left(\mathrm{g} \cdot \mathrm{min}^{-1}\right)$
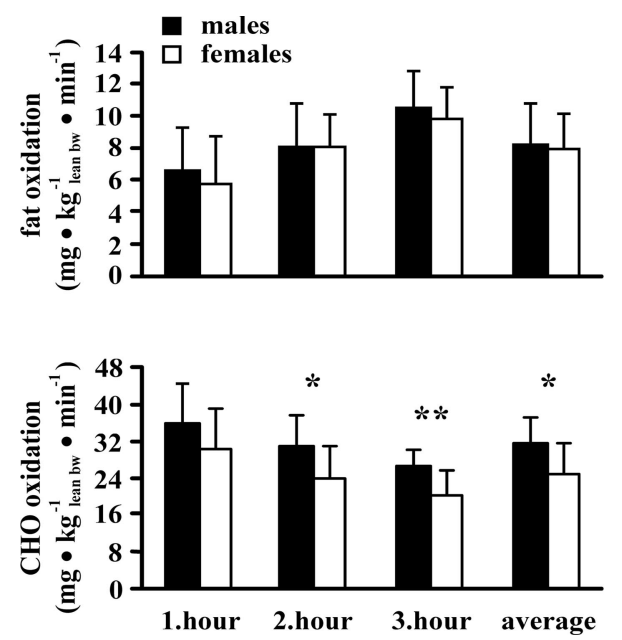

FIGURE 5-Average fat and carbohydrate (CHO) oxidation $\left(\mathrm{mg}^{\mathrm{kg}} \mathrm{kg}^{-1}\right.$ lean bw.min $\left.{ }^{-1}\right)( \pm \mathrm{SD})$ during hours $1-3$ of the endurance exercise in nine males and nine females, and the average over the whole period. The hourly increase in fat oxidation and decrease in CHO oxidation were highly significant $(P<0.001)$ in both genders. $* P<0.05$, ** $P$ $<0.01$, significant difference between males and females. 
during the endurance exercise was $0.56 \pm 0.17$ in males and $0.43 \pm 0.14$ in females (no significant difference). In contrast, average $\mathrm{CHO}$ oxidation was significantly higher $(P<$ $0.001)$ in males $\left(2.09 \pm 0.27 \mathrm{~g} \cdot \mathrm{min}^{-1}\right)$ compared with females $\left(1.32 \pm 0.33 \mathrm{~g} \cdot \mathrm{min}^{-1}\right)$. The relative amount of $\mathrm{CHO}$ and fat usage to total energy expenditure were 63 and $37 \%$ in males and 58 and $42 \%$ in females, respectively. These results show no significant difference between genders.

Energy expenditure expressed per kilogram of lean bw per hour was significantly higher $(P<0.01)$ in males $(52.7$ $\pm 5.9 \mathrm{~kJ})$ compared with females $(44.4 \pm 2.5 \mathrm{~kJ})$, whereas per workload it was the same for both genders (Table 2).

Blood parameters. There was no difference in any lactate or glucose concentrations between males and females. Lactate increased in males (resting value: $1.1 \pm 0.1$ $\mathrm{mmol} \cdot \mathrm{L}^{-1}$, end of exercise: $1.5 \pm 0.3 \mathrm{mmol} \cdot \mathrm{L}^{-1}, P<0.01$ ) and females (resting value: $1.3 \pm 0.5 \mathrm{mmol} \cdot \mathrm{L}^{-1}$, end of exercise: $1.9 \pm 0.9 \mathrm{mmol} \cdot \mathrm{L}^{-1}, P<0.05$ ), whereas glucose decreased in males (resting value: $5.4 \pm 0.3 \mathrm{mmol} \cdot \mathrm{L}^{-1}$, end of exercise: $\left.4.4 \pm 0.5 \mathrm{mmol} \cdot \mathrm{L}^{-1}, P<0.01\right)$ and females (resting value: $5.2 \pm 0.4 \mathrm{mmol} \cdot \mathrm{L}^{-1}$, end of exercise: $4.7 \pm$ $\left.0.4 \mathrm{mmol} \cdot \mathrm{L}^{-1}, P<0.001\right)$ during exercise.

\section{DISCUSSION}

The most striking findings of this study were that 1) male athletes depleted more IMCL in absolute units as well as in relative terms, whereas there was no difference in glycogen storage or reduction between gender; 2) the higher the IMCL levels were at rest, the higher the usage was during the 3-h exercise; and 3) the average total fat oxidation measured during the 3-h exercise did not differ between genders, whereas $\mathrm{CHO}$ oxidation and total energy expenditure per kilogram of lean bw was higher in males compared with females.

Because endurance training over a longer period of time enhances IMCL concentration at rest (17) and the capacity to oxidize IMCL during an endurance exercise (32), longterm training habits were evaluated. In this study, females and males were both endurance-trained healthy athletes matched for age and training history. However, differences between the types of training and intensity cannot be excluded, and have most likely led to the higher standardized $\dot{\mathrm{V}} \mathrm{O}_{2 \text { peak }}$ per kilogram of lean body weight in males compared with females. This parameter is often associated with a better training status, whereas we cannot exclude that larger IMCL utilization in males are partially due to this difference between the two groups. On the other hand, $\dot{\mathrm{V}} \mathrm{O}_{2 \max }$ tends to be lower in equally trained women than men. One reason could be differences in hemoglobin $(\mathrm{Hb})$ concentration, and the fact that $\dot{\mathrm{VO}}_{2 \text { max }}$ is not strictly a marker of training status. Nevertheless, it is also possible that the performed workloads during the training sessions were in a more optimal range to stimulate IMCL metabolism in males compared with females.

IMCL reduction is strongly correlated with IMCL levels at rest if male and female values are pooled (Fig. 4). However, if both genders are looked at separately, the correlation remains significant in males-even without the data from the male volunteer with the exceptionally high IMCL levels at rest that could influence this result most prominentlywhereas it loses significance for females. Because the distribution of values for females is much closer than for males, this finding may partially result from the smaller dynamic range that could jeopardize the correlation of noisy data. Previous transversal studies confirm that higher IMCL concentrations lead to a greater degree of IMCL breakdown during exercise $(16,30,36)$. An analogous finding has been described for glycogen utilization (23).

Changes of IMCL levels between end of exercise and acquisition of ${ }^{1} \mathrm{H}-\mathrm{MR}$ spectra cannot be totally excluded. However, several studies (e.g., (9)) allow the assumption that changes following exercise are very slow, such that a delay of about $60 \mathrm{~min}$ in this experiment should not dramatically influence the results and, in particular, should not introduce differences between the groups. In addition, absolute quantification of IMCL was based on the signal of water, and thus could be influenced by changes in the total water content. However, two control experiments make such changes unlikely: (1) estimations of the muscle volume on the MR localizer images before and after exercise did not indicate any regular changes, and (2) the signal from creatine (also visible in the 1H-MR spectrum) did not show any systematic variations pre- versus postexercise.

To make results from the two groups comparable, it was necessary to require equal relative performance of both genders, standardized by $\dot{\mathrm{VO}}_{2 \text { peak }}$ and average maximal heart rate. In addition, both genders scored the perceived exertion as "somewhat hard," and physiological parameters averaged over the 3-h exercise, such as the average percentage of $\dot{\mathrm{V}} \mathrm{O}_{2 \text { peak }}$ and of maximal heart rate, RER, energy used per workload (Table 2), and average oxygen uptake per workload were the same in both genders. The average total fat oxidation measured during the $3 \mathrm{~h}$ was similar in both genders. Because males used more IMCL than females, the latter had to use another fat source as energy supply, most probably free fatty acids. Because indirect calorimetry gives estimates for whole body lipid oxidation, one has to consider that fat oxidation in the liver could contribute to the results.

Additionally, $\mathrm{CHO}$ oxidation and total energy expenditure per kilogram of lean body weight were higher in males compared with females. The short-term diet of the subjects before exercise has been closely monitored (Table 1), and showed a trend to slightly higher fat intake in males compared with females. Even if this trend did not reach statistical significance for fat uptake relative to body weight, relative to lean body weight, or relative to total energy consumed, one has to consider that the slightly higher IMCL levels at rest in males could be partially due to this factor. On the other hand, there was no correlation found between the fat intake during the $2 \mathrm{~d}$ before the main exercise and the IMCL stores in $m$. vastus intermedius at rest. Because Décombaz and coworkers (8) showed no difference in IMCL replenishment when they fed the subjects with 40 or $70 \%$ fat energy, one could argue that the additional fat-rich snacks 
before the first MR examination were sufficient to fill the IMCL stores such that any minor differences in the diet of the preceding $2 \mathrm{~d}$ would have been compensated. In addition, females showed a higher skeletal muscle triglyceride uptake compared with males after the same amount of fat intake (30).

Because type I fibers contain three times more IMCL than type II fibers (15) and are predominantly recruited during endurance exercise, a systematic dissimilarity between the types of muscle fibers could explain gender-specific differences in IMCL levels and depletion. However, literature on gender-specific fiber type distribution is controversial. Whereas some studies showed less type I fibers in m.vastus lateralis in females compared to males (18), other groups did not detect significant differences in untrained females and males (29) or endurance-trained subjects of both genders (30). It is also noteworthy that the cross-sectional area of all three major fiber types was larger for males compared to the respective fiber types in females (29). Bachmann and coworkers (2) observed larger absolute changes of IMCL in soleus compared with tibialis anterior muscle, and explain this observation by differences in the fiber type composition.

Because IMCL (acquired from m.vastus intermedius) and glycogen (originating from all vastus muscles) have not been acquired from exactly the same volume, different recruitment patterns in males and females during cycling could influence the results. However, studies on muscle fiber type composition of the $m$. vastus lateralis found no significant differences between males and females (29), which could be indicative of different recruitment patterns. In addition, a recent study shows that during a 3-h cycling exercise there was no difference in IMCL utilization between m.vastus lateralis and intermedius (37).

It is unclear how the hormonal status may influence the IMCL content specifically. Some evidence has been found that the adrenergic system may play an important role in the activation of lipolysis of IMCL. Cleroux and coworkers (7) showed that IMCL utilization during an endurance exercise was completely blocked by a nonselective beta-blockade. In the study of Froberg et al. (10) a 4-h infusion of noradrenalin resulted in a significant reduction of resting IMCL concentration in male subjects. In addition, the catecholamine response is greater in men compared with women during the same relative workload (13), resulting in a higher activity of the hormone-sensitive lipase, which is responsible for IMCL hydrolysis (19). Other groups (e.g., (12)) investigated the variations of the sex hormones during the menstrual cycle and their influence on energy metabolism. Perseghin et al. (22) presented various explanations for the differences between IMCL accumulation and utilization between genders. For instance, they suggest that nonobese men may maintain low IMCL content due to a greater ability to metabolize fatty acids in the oxidative pathways. Unfortunately, no venous blood samples were taken in this study, therefore no plasma metabolites (e.g., hormones or free fatty acids) could be determined.

This study found higher IMCL levels and in particular a higher depletion in males compared with females. This is in disagreement with other studies, which found enhanced resting IMCL and utilization during exercise in females compared with males (30), or no difference in IMCL reduction between genders during exercise (36). The reason for this discrepancy is not obvious. It could be explained by the applied method (30), by the difference in exercise duration $(30,36)$, or by comparing with other studies in the recruitment of a different type of subject (sedentary instead of well-trained athletes), different diet regimes (2), or in the measurement of different muscle groups $(22,31)$.

Considering IMCL depletion, exercise studies are strongly dependent on the specific workload, duration, and intensity. A major difference between the other two investigations where males and females were directly compared $(30,36)$ and this study is the duration of the workload. In the cited publications it was not longer than $90 \mathrm{~min}$.

However, White et al. (36), who also used ${ }^{1} \mathrm{H}-\mathrm{MRS}$ to determine IMCL before and after exercise in females and males, measured $20 \%$ higher resting IMCL and $30 \%$ higher IMCL utilization in males compared with females if they calibrated IMCL by the water signal, as it is done in our study. The lack of significance in these results is probably due to the large between-subject variability of IMCL decrements in both gender.

An additional, possibly important factor influencing IMCL metabolism concerns the choice of the pedal rate. There is an increased recruitment of type II muscle fibers, which contain less IMCL than type I fibers, at a higher crank speed from 50 to $120 \mathrm{rpm}$ (20). According to this study, the mean optimal cadence was $70 \mathrm{rpm}$ for $200 \mathrm{~W}$ and $57 \mathrm{rpm}$ for $100 \mathrm{~W}$. This would mean that the cadence chosen for our female subjects $(70-75 \mathrm{rpm})$ was too high, as they cycled the 3-h exercise with an average of $120 \mathrm{~W}$. This in turn could be a reason for the lower IMCL degradation in females. To our knowledge, there is no other endurance exercise study that looked at IMCL degradation and at the same time strictly controlled crank speed.

\section{CONCLUSION}

This study, investigating well-trained athletes, revealed a considerable decrease in IMCL concentrations in both genders during a submaximal 3-h endurance exercise. Additionally, the reduction of IMCL during the 3-h trial was larger in males compared with females, whereas glycogen usage and the relative contribution of fat and $\mathrm{CHO}$ to total energy used were the same. Because the relative parameters and the methodological variations were minimized, in these trained individuals, a gender-specific difference in IMCL utilization may explain the results. However, $\dot{\mathrm{VO}}_{2 \text { peak }}$ per kilogram of lean bw was higher in males compared with females. This fact points to a better training state in males and may have partly contributed to the gender differences in IMCL utilization found in this study.

We are very grateful to $\mathrm{K}$. Zwygart-Brügger and B. Jung for their assistance during the MR measurements, to $\mathrm{H}$. Hoppeler for his help 
with initial experiments, to J.-P. Schmid and R. Steiner for the generous offer to use their lab space, and to J. Décombaz from the Nestlé Research Center in Lausanne for critical review of the manu-

\section{REFERENCES}

1. Achten, J., M. Gleeson, and A. E. Jeukendrup. Determinationof the exercise intensity that elicits maximal fat oxidation. Med.Sci. Sports Exerc. 34:92-97, 2002.

2. Bachmann, O. P., D. B. Dahl, K. Brechtel, et al. Effects of intravenous and dietary lipid challenge on intramyocellular lipid content and the relation with insulin sensitivity in humans. Diabetes 50:2579-2584, 2001

3. Boesch, C., J. Decombaz, J. Slotboom, and R. Kreis. Observation of intramyocellular lipids by means of $1 \mathrm{H}$ magnetic resonance spectroscopy. Proc. Nutr. Soc. 58:841-850, 1999.

4. Boesch, C., J. Slotboom, H. Hoppeler, and R. Kreis. In vivo determination of intra-myocellular lipids in human muscle by means of localized 1H-MR-spectroscopy. Magn. Reson. Med. 37:484-493, 1997.

5. Borg, G. A. Psychophysical bases of perceived exertion. Med. Sci. Sports Exerc. 14:377-381, 1982.

6. Carter, S. L., C. Rennie, and M. A. Tarnopolsky. Substrate utilization during endurance exercise in men and women after endurance training. Am. J. Physiol. Endocrinol. Metab. 280:E898E907, 2001.

7. Cleroux, J., P. Van Nguyen, A. W. Taylor, and F. H. Leenen. Effects of beta 1- vs. beta $1+$ beta 2-blockade on exercise endurance and muscle metabolism in humans. J. Appl. Physiol. 66:548-554, 1989.

8. Decombaz, J., M. Fleith, H. Hoppeler, R. Kreis, and C. Boesch. Effect of diet on the replenishment of intramyocellular lipids after exercise. Eur. J. Nutr. 39:244-247, 2000.

9. Decombaz, J., B. Sснмitт, M. Ith, et al. Post-exercise fat intake repletes intramyocellular lipids, but no faster in trained than in sedentary subjects. Am. J. Physiol. 281:R760-R769, 2001.

10. Froberg, S. O., E. Hultman, and L. H. Nilsson. Effect of noradrenaline on triglyceride and glycogen concentrations in liver and muscle from man. Metabolism 24:119-126, 1975.

11. Guo, Z., B. Burguera, and M. D. Jensen. Kinetics of intramuscular triglyceride fatty acids in exercising humans. J. Appl. Physiol. 89:2057-2064, 2000.

12. Horton, T. J., E. K. Miller, D. Glueck, and K. Tench. No effect of menstrual cycle phase on glucose kinetics and fuel oxidation during moderate-intensity exercise. Am. J. Physiol. Endocrinol. Metab. 282:E752-E762, 2002.

13. Horton, T. J., M. J. Pagliassotti, K. Hobbs, and J. O. Hill. Fuel metabolism in men and women during and after long-duration exercise. J. Appl. Physiol. 85:1823-1832, 1998.

14. Howald, H., C. Boesch, R. Kreis, et al. Content of intramyocellular lipids derived by electron microscopy, biochemical assays, and (1)H-MR spectroscopy. J. Appl. Physiol. 92:2264-2272, 2002.

15. Howald, H., H. Hoppeler, H. Claassen, O. Mathieu, and R. StRAub. Influences of endurance training on the ultrastructural composition of the different muscle fiber types in humans. Pflugers Arch. 403:369-376, 1985.

16. Johnson, N. A., S. R. Stannard, K. Mehalski, et al. Intramyocellular triacylglycerol in prolonged cycling with high- and lowcarbohydrate availability. J. Appl. Physiol. 94:1365-1372, 2003.

17. Kiens, B., B. Essen-Gustavsson, N. J. Christensen, and B. Saltin. Skeletal muscle substrate utilization during submaximal exercise in man: effect of endurance training. J. Physiol. 469:459-478, 1993.

18. Komi, P.V., and J. Karlsson. Skeletal muscle fibre types, enzyme activities and physical performance in young males and females. Acta Physiol. Scand. 103:210-218, 1978.

19. Langfort, J., M. Donsmark, T. Ploug, C. Holm, and H. Galbo. Hormone-sensitive lipase in skeletal muscle: regulatory mechanisms. Acta Physiol. Scand. 178:397-403, 2003.

20. Macintosh, B. R., R. R. Neptune, and J. F. Horton. Cadence, script. This study was supported by the Swiss Society of Nutrition Research (Project 290) and by the Swiss National Science Foundation (3100-065315.01).

power, and muscle activation in cycle ergometry. Med. Sci. Sports Exerc. 32:1281-1287, 2000.

21. Peronnet, F., and D. Massicotte. Table of nonprotein respiratory quotient: an update. Can. J. Sport Sci. 16:23-29, 1991.

22. Perseghin, G., P. Scifo, E. Pagliato, et al. Gender factors affect fatty acids-induced insulin resistance in nonobese humans: effects of oral steroidal contraception. J. Clin. Endocrinol. Metab. 86: 3188-3196, 2001.

23. Rico-Sanz, J., M. Zehnder, R. Buchli, M. Dambach, and U. BOUTELLIER. Muscle glycogen degradation during simulation of a fatiguing soccer match in elite soccer players examined noninvasively by 13C-MRS. Med. Sci. Sports Exerc. 31:1587-1593, 1999.

24. Roepstorff, C., C. H. Steffensen, M. Madsen, et al. Gender differences in substrate utilization during submaximal exercise in endurance-trained subjects. Am. J. Physiol. Endocrinol. Metab. 282:E435-E447, 2002.

25. Romisn, J. A., E. F. Coyle, L. S. Sidossis, et al. Regulation of endogenous fat and carbohydrate metabolism in relation to exercise intensity and duration. Am. J. Physiol. 265:E380-E391, 1993.

26. Ruby, B. C., A. R. Coggan, and T. W. ZDERIC. Gender differences in glucose kinetics and substrate oxidation during exercise near the lactate threshold. J. Appl. Physiol. 92:1125-1132, 2002.

27. Schick, F., B. Eismann, W. I. Jung, H. Bongers, M. Bunse, and O LuTz. Comparison of localized proton NMR signals of skeletal muscle and fat tissue in vivo: two lipid compartments in muscle tissue. Magn. Reson. Med. 29:158-167, 1993.

28. Sinning, W. E., D. G. Dolny, K. D. Little, et al. Validity of "generalized" equations for body composition analysis in male athletes. Med. Sci. Sports Exerc. 17:124-130, 1985.

29. Staron, R. S., F. C. Hagerman, R. S. Hikida, et al. Fiber type composition of the vastus lateralis muscle of young men and women. J. Histochem. Cytochem. 48:623-629, 2000.

30. Steffensen, C. H., C. Roepstorff, M. Madsen, and B. Kiens Myocellular triacylglycerol breakdown in females but not in males during exercise. Am. J. Physiol. Endocrinol. Metab. 282:E634E642, 2002

31. Thamer, C., J. Machann, O. Bachmann, et al. Intramyocellular lipids: anthropometric determinants and relationships with maximal aerobic capacity and insulin sensitivity. J. Clin. Endocrinol. Metab. 88:1785-1791, 2003.

32. van Loon, L. J., R. Koopman, J. H. Stegen, A. J. Wagenmakers, H. A. KeIZER, and W. H. SARIS. Intramyocellular lipids form an important substrate source during moderate intensity exercise in endurance-trained males in a fasted state. J. Physiol. 553:611-625, 2003.

33. Watt, M. J., G. J. Heigenhauser, D. J. Dyck, and L. L. Spriet. Intramuscular triacylglycerol, glycogen and acetyl group metabolism during $4 \mathrm{~h}$ of moderate exercise in man. J. Physiol. 541: 969-978, 2002.

34. Watt, M. J., G. J. Heigenhauser, and L. L. Spriet. Intramuscular triacylglycerol utilization in human skeletal muscle during exercise: is there a controversy? J. Appl. Physiol. 93:1185-1195, 2002.

35. Wendling, P. S., S. J. Peters, G. J. Heigenhauser, and L. L. SPRIET. Variability of triacylglycerol content in human skeletal muscle biopsy samples. J. Appl. Physiol. 81:1150-1155, 1996.

36. White, L. J., M. A. Ferguson, S. C. McCoy, and H. Kim. Intramyocellular lipid changes in men and women during aerobic exercise: a (1)H-magnetic resonance spectroscopy study. J. Clin. Endocrinol. Metab. 88:5638-5643, 2003.

37. Zehnder, M., P., SAillen, R., Kreis, C., and Boesch, P. VermaTHEN, Evaluation of intramyocellular lipids concentration in the different thigh and calf muscles before and after endurance exercise. Proceedings of the International Society for Magnetic Resonance in Medicine 13, 798. 2005. 